\title{
Letter \\ How much insulin is acceptable following aneurysmal subarachnoid hemorrhage?
}

John F Stover

UniversitätsSpital Zürich, Departement Chirurgie, Abteilung Chirurgische Intensivmedizin, Rämistrasse 100, 8091 Zürich, Switzerland

Corresponding author: John F Stover, john.stover@usz.ch

Published: 27 February 2008

This article is online at http://ccforum.com/content/12/1/410

(c) 2008 BioMed Central Ltd

See related research by Schlenk et al., http://ccforum.com/content/12/1/R9
Critical Care 2008, 12:410 (doi:10.1186/cc6783)

3 hours following insulin infusion. Schlenk and colleagues interpret these changes as an increase in cerebral glucose utilization. This interpretation, however, is difficult to understand since cerebral glucose uptake occurs independently of insulin and the blood glucose levels remained stable.

The calculated increased lactate/glucose ratio [3] suggests sustained glycolysis-driven lactate production over time. Whether this is a consequence of insulin treatment (for which specific data are missing), is a consequence of underlying injury with variable degrees of damage, is caused by different starting time points of insulin administration, is overshadowed by different degrees of sedation (awake, deep barbiturate coma, hypothermia), or is overshadowed by varying penetration depths of the microdialysis probes remains unclear. In addition, the exact nutritional regimen also needs to be explained. Addition of these important pieces of information would help one to draw appropriate conclusions.

\section{Author's response}

Florian Schlenk and Asita Sarrafzadeh

We are pleased that our work evokes the interest of the readership. Indeed, avoidance of hypoglycemia is of major importance in brain-lesioned patients, which explains our moderate regimen for glycemic control (target range 80-140 mg/dl) [1].

Unexpectedly, 3 hours after insulin onset, the cerebral glucose decreased despite stable blood levels [1]. The underlying mechanisms remain unclear, as physiologic cerebral glucose uptake seems to occur independently of insulin [4]. Yet insulin receptors are widely spread in cerebral tissue, and the injured brain might react differently. The risk of cerebral glucose depletion is stressed by severe metabolic derangements demonstrated during lowered brain glucose in traumatic brain injury and subarachnoid hemorrhage $[5,6]$.

Cerebral glucose levels can be influenced by various factors, which cannot all be controlled in a clinical setting. Interindividual differences as quoted by Dr Stover (catheter depth or degree of damage and sedation), however, can hardly explain longitudinal changes over time, and barbiturates or hypothermia were not applied. Nutritionrelated effects should be mediated by glucose changes, which were recorded. Ischemia could also widely be excluded [1], and an increase in the lactate/glucose ratio without changes in lactate or pyruvate is unspecific and does not support energetic impairment or hyperglycolysis $[5,7]$. 
Finally, despite using different insulin starting points, we observed a synchronic effect starting 3 hours after insulin onset in an analysis of high temporal resolution. This is a strong indicator that the decrease in brain glucose was not just a delayed reaction to the hemorrhage but was in some way related to insulin treatment. The biochemical processes behind this reaction, however, remain to be elucidated.

\section{Competing interests}

The author declares that they have no competing interests.

\section{References}

1. Schlenk F, Graetz D, Nagel A, Schmidt M, Sarrafzadeh AS: Insulin-related decrease in cerebral glucose despite normoglycemia in aneurysmal subarachnoid hemorrhage. Crit Care 2008, 12:R9.

2. van den Berghe $G$, Wouters $P$, Weekers F, Verwaest $C$, Bruyninckx F, Schetz M, Vlasselaers D, Ferdinande P, Lauwers P, Bouillon R: Intensive insulin therapy in the critically ill patients. $N$ Engl J Med 2001, 345:1359-1367.

3. Thomale UW, Griebenow M, Mautes A, Beyer TF, Dohse NK, Stroop R, Sakowitz OW, Unterberg AW, Stover JF: Heterogeneous regional and temporal energetic impairment following controlled cortical impact injury in rats. Neurol Res 2007, 29: 594-603.

4. Cranston I, Marsden P, Matyka K, Evans M, Lomas J, Sonksen P, Maisey M, Amiel SA: Regional differences in cerebral blood flow and glucose utilization in diabetic man: the effect of insulin. J Cereb Blood Flow Metab 1998, 18:130-140.

5. Schlenk F, Nagel A, Graetz D, Sarrafzadeh AS: Hyperglycemia and cerebral glucose in aneurysmal subarachnoid hemorrhage. Intensive Care Med 2008, doi:10.1007/s00134-008-1044-5.

6. Vespa PM, McArthur D, O'Phelan K, Glenn T, Etchepare M, Kelly D, Bergsneider M, Martin NA, Hovda DA: Persistently low extracellular glucose correlates with poor outcome 6 months after human traumatic brain injury despite a lack of increased lactate: a microdialysis study. J Cereb Blood Flow Metab 2003, 23:865-877.

7. Oertel MF, Schwedler M, Stein M, Wachter D, Scharbrodt W, Schmidinger A, Boker DK: Cerebral energy failure after subarachnoid hemorrhage: the role of relative hyperglycolysis. J Clin Neurosci 2007, 14:948-954. 